BMJ Open

Sport \&

Exercise

Medicine

\title{
Attitudes towards protective headgear in UK rugby union players
}

\author{
Andrew Barnes, James L Rumbold, Peter Olusoga
}

To cite: Barnes A, Rumbold JL, Olusoga $P$. Attitudes towards protective headgear in UK rugby union players. BMJ Open Sport Exerc Med 2017;3:e000255. doi:10.1136/bmjsem-2017000255

Accepted 11 September 2017
CrossMark

Academy of Sport and Physical Activity, Sheffield Hallam University, Sheffield, UK

Correspondence to Dr Andrew Barnes; a. barnes@shu.ac.uk

\section{ABSTRACT \\ Background/aim Concussions in rugby union pose a major threat to player welfare. Research has found protective headgear offers no significant protection against concussions but suggests a large proportion of players perceive headgear to be effective in preventing concussions. This study aimed to explore UK rugby union players' attitudes towards wearing protective headgear.}

Methods 545 rugby union players ( $85 \%$ male) from a range of playing standards completed an online survey. Quantitative and qualitative data were collected on player attitudes towards protective headgear use. Descriptive statistics, multiple regressions and content analysis were used to analyse the responses.

Results $37 \%$ of players believed that headgear was effective in preventing head injuries. Playing group was found to be inversely associated with headgear effectiveness $\left(\Delta R^{2}=0.01, B=-0.13, \mathrm{p}=0.02\right)$, with youth players holding stronger beliefs that headgear is effective at preventing head injuries compared with all senior groups. The main reasons cited for wearing headgear related to protection from minor injuries $(55 \%)$ with only $10 \%$ of responses related to concussion prevention.

Conclusions There appears to be a good awareness in UK players that protective headgear is not effective at preventing concussions. Continued education is vital to ensure players are fully aware of the limitations of headgear, and players who wear it do not engage in overly reckless behaviours as a result.

\section{INTRODUCTION}

The UK has the highest rugby union participation levels in the world with approximately 2.7 million children and adults playing the sport. ${ }^{1}$ Despite high participation rates, head injuries are common and pose a serious threat to player welfare. The incidence of match-play concussions in men's rugby union has been reported at 4.73 per 1000 player match hours. ${ }^{2}$ Evidence also suggests there is variation in injury risk between playing levels and sexes, with subelite players at a greater risk of concussion than either elite, youth or women's playing groups. ${ }^{2}$ The consequences of concussion in youth players can be extremely damaging, with prolonged recovery periods and more conservative

\section{What are the new findings}

- The primary reason players wore protective headgear related to the prevention of minor injuries rather than more serious head injuries such as concussions.

- There appeared to be a greater awareness in UK players that protective headgear was not effective at preventing concussion compared with previous studies.

- Continued education is vital to ensure players are fully aware of the limitations of headgear, and players who wear it do not engage in overly reckless behaviours as a result.

approaches for injury management often necessary. ${ }^{3} 4$ In this group, the risk of sustaining a concussion as a result of participating in any game or practice (player exposure) has been found to be higher in rugby union (4.18 per 1000 player exposures) compared with other contact sports such as ice hockey (1.20 per 1000 player exposures) and american football (0.53 per 1000 player exposures). ${ }^{5}$ Also this risk has been found to increase over the course of a season. $^{2} 67$

Protective headgear is commonplace but not mandatory in rugby union. It is designed to reduce the risk of superficial head injuries (lacerations and abrasions) but not to prevent more serious impact injuries such as concussions. ${ }^{8-10}$ Current evidence is equivocal as to the extent to which using headgear is associated with reduced incidence and severity of concussions. ${ }^{8} 9$ 11-15 Players who wear headgear regularly have been found to be less likely to sustain a concussion compared with those who never wore it. ${ }^{12} 14$ However, several studies in youth $^{815}$ and senior rugby ${ }^{8}$ have found no difference in concussion rates between players who did and did not wear headgear. A recent systematic review of concussion prevention strategies concluded that headgear may prevent superficial head injuries but does not prevent concussions, ${ }^{11}$ yet 
research suggests that a significant proportion of players (up to 60\%) believe that wearing headgear prevents severe head injuries, including concussions. ${ }^{16-}$

${ }^{8}$ Players who wore headgear reported feeling safer, more confident, able to play more aggressively and tackle harder. ${ }^{16}{ }^{18}$ In youth players, common reasons cited for not wearing headgear included lack of comfort and ventilation, as well as cost. Interestingly, only $7 \%$ of players who choose not to wear headgear believed that it 'does not work' in preventing head injuries. These initial findings are worrying and suggest that many players may perceive headgear to be an effective way of preventing concussion, ${ }^{16-18}$ a belief not well supported by research. ${ }^{8} 91115$

The current study seeks to extend previous research in several ways. First, it aims to examine player attitudes towards headgear use in greater detail through the adoption of a mixed-methods approach, using both Likert scale and qualitative responses to provide a richer understanding of the area. Second, knowledge of how attitudes might vary between playing subgroups is necessary for targeting educational initiatives towards specific groups. For example, female players represent approximately $23 \%$ of all players worldwide yet, to date, no studies have examined their attitudes towards protective headgear. More in-depth analysis of a broader spectrum of subgroups based on a larger sample of players is required to help understand how wearing headgear fits within the modern game. Therefore, the purpose of this study was to examine UK rugby union players' attitudes towards wearing protective headgear.

\section{METHODS}

\section{Participants}

Following institutional ethics approval, data were collected via an online survey distributed through social media sites and the mailing lists of rugby clubs. Seven hundred and twenty-eight responses were recorded, 207 of which were discarded due to incomplete data, leaving 545 usable questionnaires from players representing 187 different clubs and schools

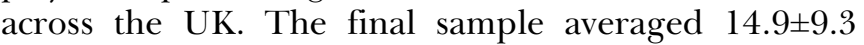
years playing experience, was $85 \%$ male and was representative of a range of playing levels (youth: 10\%, subelite: $79 \%$ and semiprofessional/professional: $11 \%$ ). Front row players comprised $27 \%$ of respondents, $43 \%$ were back-five forwards and $30 \%$ were backs.

\section{Survey}

Section one gathered demographic information (eg, sex, age, rugby experience, playing position, competitive level and participants' history of head injuries) and sought to identify participants who did/did not regularly wear headgear. Section two was completed only by those participants who wore headgear regularly and contained questions about their attitudes towards headgear (eg, reasons for wearing it, its effectiveness in injury prevention and whether it affects performance). Section three was completed only by those who did not regularly wear headgear and contained questions about their attitudes towards headgear. Attitudinal questions (eg, 'how much do you feel that wearing protective headgear impacts upon your performance when playing rugby?') were answered using a 5-point Likert scale (eg, $1=$ "not at all', $5=$ 'a great deal'). Participants were asked to elaborate on their answers using open-ended text boxes. This concurrent triangulation, mixed-method design allowed for descriptive and interpretive information to be obtained. The survey was pilot tested with 10 players (two youth, four subelite and four semiprofessional). Based on their feedback, minor changes were made to the phrasing of some questions before the survey was distributed. Responses were recorded between March and June 2016.

\section{Data analysis}

Quantitative data were analysed in SPSS (V.23), and descriptive statistics were produced to explore demographic information, headgear usage and history of injuries. Following checks for parametric assumptions, preliminary correlations were performed followed by multiple regressions to identify significant predictors for two dependent variables: the degree to which protective headgear was perceived to be effective in preventing head injuries and the extent to which protective headgear should be made compulsory. For all respondents $(n=545)$, dependent variables were examined with group (dummy coded separately for junior, female, subelite and professional and semiprofessional groups), player position (dummy coded as $0=$ forwards, $1=$ backs), playing experience (years) and headgear use as predictors in the model. For players who regularly wore headgear $(n=178)$, multiple regressions were run for the same dependent variables, with the following predictors entered in the model: perceived importance of wearing headgear in training, perceived importance of wearing headgear in matches, perceived impact of wearing headgear on performance and the extent to which wearing headgear changes the way you play.

Open-ended survey responses were analysed using a combination of inductive and deductive content analysis procedures. $^{19}$ General dimensions were deductively derived based on previous research. ${ }^{16-18}$ Within each general dimension, inductive content analysis procedures were followed. Raw data responses were independently coded by three researchers, organised into groups of like responses, and higher order themes of greater generality were identified. To ensure the trustworthiness of data, consensus was reached at each level of analysis through extensive discussion among the research team. General dimensions were first analysed within group; however, due to there being little differences in the emerging themes 
between groups, the dimensions presented are representative of all respondents.

\section{RESULTS}

\section{Headgear use and injury}

Of those surveyed $(n=545), 67 \%(n=363)$ of players reported wearing headgear at some point while playing, but only $36 \%(\mathrm{n}=195)$ wore it regularly during matches and $12 \%(n=63)$ during training. Of those who reported wearing headgear but did not wear it regularly, 33\% $(\mathrm{n}=61)$ had worn it temporarily as a result of injury and $67 \%(n=124)$ tried wearing it but did not like it. Of those surveyed, $82 \%$ reported experiencing a head injury while playing; of these, concussions (58\%), lacerations and abrasions $(52 \%)$ and ear injuries (32\%) were the most commonly reported. Of those players who regularly wore headgear, $63 \%$ reported experiencing one or more concussions as a result of playing rugby, whereas in those who did not regularly wear headgear this figure was $55 \%$.

\section{Attitudes towards wearing headgear}

Of those surveyed $(n=545), 37 \%$ believed that headgear was either 'quite' or 'extremely' effective in preventing head injuries. This percentage reduced when considering only those participants who had reported having previously had a concussion $(n=90 / 290,31 \%)$, laceration and abrasions $(\mathrm{n}=77 / 257,30 \%)$ or ear injuries $(n=49 / 154,32 \%)$. Based on all respondents $(n=545)$, the initial regression model including only regular headgear use showed that this was strongly associated with the belief in headgear effectiveness $\left(\Delta R^{2}=0.13\right.$, $\mathrm{B}=0.72, \quad \mathrm{SE}=0.08, \quad \beta=0.36, \quad 95 \%$ CI 0.56 to 0.88 , $\mathrm{p}=0.000$ ). When youth playing group was added to the model, it was found that this group was positively associated with headgear effectiveness $\left(\Delta R^{2}=0.01, \mathrm{~B}=0.37\right.$, $\mathrm{SE}=0.14, \beta=0.11,95 \%$ CI 0.10 to $0.65, \mathrm{p}=0.01)$. Youth players held stronger beliefs that headgear is effective at preventing head injuries in comparison with subelite, semiprofessionals/professionals and women combined. It was found that neither playing position $(\mathrm{p}=0.227)$ nor playing experience $(p=0.751)$ was associated with perceptions of headgear effectiveness. When checking the assumptions of the model, the variation inflation factor statistics revealed no issues with multicollinearity. In addition, the residuals had a normal distribution and the Durbin-Watson statistic was 2.01, indicating that the assumption of independent errors was met.

\section{Attitudes of players who wear headgear regularly}

When considering only those players who wore protective headgear regularly $(n=178)$, multiple regressions found perceived importance of wearing headgear in matches was positively associated with a belief that headgear is effective in preventing head injuries $\left(\Delta R^{2}=0.17\right.$, $\mathrm{B}=0.35, \quad \mathrm{SE}=0.07, \beta=0.34,95 \%$ CI 0.20 to 0.49 , $\mathrm{p}=0.000)$. Eight higher order themes represented reasons for wearing headgear (table 1). Fifty-five per cent of the raw data responses indicated that players wore headgear to protect themselves from minor injuries. For example, one player suggested that headgear was valuable for 'protecting my head from unnecessary knocks and my ears from damage in the scrum', while another felt headgear 'reduces facial injuries if playing in the forwards'. In another theme, $13 \%$ of responses suggested that players 'feel more confident' when wearing headgear, with one player suggesting you have 'more confidence putting your head wear it hurts'. Comprising another higher order theme, $12 \%$ of responses suggested that players started wearing headgear to give them more confidence after previous head injuries. Only $10 \%$ of the raw data responses suggested that players wore headgear to 'protect the head and brain from serious injury and concussion'.

\section{Attitudes of players who do not regularly wear headgear}

When considering only those players who did not wear headgear regularly $(n=367)$, six higher order themes emerged, representing their reasons (table 2). The largest of these (36\% of responses) referred to the general discomfort of wearing headgear. Respondents suggested that headgear was 'uncomfortable and too hot' and 'felt claustrophobic'. Twenty-four per cent of player responses suggested that their position did not warrant them wearing headgear. Specifically, as one player suggested, 'I'm a winger so I'm not in scrums'. In addition to the discomfort described, $23 \%$ of responses indicated that players felt their senses were restricted by wearing headgear. For example, participants discussed 'restricted vision' and being 'unable to hear' when wearing headgear.

\section{Attitudes towards the mandatory use of headgear}

Overall, $13 \%$ of respondents believed headgear should be mandatory. Regular headgear use was associated with a belief that headgear should be made mandatory $\left(\Delta R^{2}=0.02, \mathrm{~B}=0.29, \mathrm{SE}=0.10,95 \%\right.$ CI 0.10 to 0.49 , $\mathrm{p}=0.004)$. Neither playing position nor years' experience was associated with this outcome variable. However, group was found to be inversely associated $\left(\Delta R^{2}=0.03, \quad \mathrm{~B}=-0.25, \quad \mathrm{SE}=0.07, \quad 95 \% \mathrm{CI} \quad-0.37\right.$ to $-0.12, \mathrm{p}=0.000)$, with youth players holding stronger beliefs that headgear should be made mandatory in comparison with subelite $(\mathrm{p}=0.01)$, semiprofessional/ professional $(\mathrm{p}=0.05)$ and women $(\mathrm{p}=0.05)$.

\section{DISCUSSION}

This study explored attitudes towards the use of protective headgear among UK rugby union players. Results revealed that $37 \%$ of players surveyed believed that headgear was either 'quite' or 'extremely' effective in preventing head injuries, with youth players more likely to hold this view than other playing groups. Our findings suggest that although headgear use was 
Table 1 Reasons for regularly wearing protective headgear

\begin{tabular}{|c|c|}
\hline Higher order theme ( $\%$ of responses) & Example responses \\
\hline Prevention of minor injuries (55\%) & $\begin{array}{l}\text { Stop my ears rubbing in the scrum. } \\
\text { Protects from cuts and bumps. } \\
\text { Protection of ears in scrum and studs in rucks. } \\
\text { To stop my ears from getting ripped off. }\end{array}$ \\
\hline General confidence (13\%) & $\begin{array}{l}\text { A bit more of a confidence booster to throw myself at the opposition. } \\
\text { I feel more confident going into contact wearing it. } \\
\text { It builds my confidence in tackling and rucking/mauling. } \\
\text { More confidence putting your head where it hurts. Helps to take away any worry } \\
\text { of a boot coming into contact with your head. }\end{array}$ \\
\hline
\end{tabular}

\begin{tabular}{|c|c|}
\hline Confidence after previous injury (12\%) & $\begin{array}{l}\text { I have previously suffered a couple of serious concussions as a result of impacts } \\
\text { in the tackle or ruck areas, as a result I began wearing headgear and have not } \\
\text { suffered again. } \\
\text { I have been out of games due to a head injury before, so wearing headgear } \\
\text { prevents those kinds of injuries. } \\
\text { Began wearing after a series of concussions. Although I am aware that the } \\
\text { headgear does not prevent concussions, it provided a feeling of protection. }\end{array}$ \\
\hline Prevents concussions (10\%) & $\begin{array}{l}\text { Reduce the chance of a repeated concussion. } \\
\text { Protect head and brain from injury and concussion. } \\
\text { I have had concussion and some bad knocks when not wearing it and haven't } \\
\text { had concussion or any bad knocks when I have been wearing it. } \\
\text { Softens impact to the head in contact, minimising risk of getting knocked out. }\end{array}$ \\
\hline Keep hair out of the way (3\%) & $\begin{array}{l}\text { Stops my hair getting pulled in my face so I can see properly. } \\
\text { It was to keep the hair out of my face without looking like a girl with a pony tail. }\end{array}$ \\
\hline Habit/routine (3\%) & $\begin{array}{l}\text { Always wore one as a junior and just carried on. More of a mind-set thing now. } \\
\text { I have always worn headgear; it would feel alien to play without it now. }\end{array}$ \\
\hline Comfort $(2 \%)$ & $\begin{array}{l}\text { I don't like my ears being exposed. } \\
\text { Warm in the winter. }\end{array}$ \\
\hline Parents (1\%) & $\begin{array}{l}\text { My parents make me wear it. } \\
\text { It stops mum complaining. }\end{array}$ \\
\hline
\end{tabular}

associated with an increased belief of effectiveness in preventing head injuries, only a small proportion of responses indicated that players wore headgear to prevent concussions. While there seems to be a good awareness about the limitations of headgear use in the population surveyed, continued education on the issues is needed to ensure similar attitudes are maintained. At the youth level, initiatives should focus on players and on parents and coaches to reinforce appropriate attitudes towards headgear use. Player and coach education strategies to reduce injury rates have previously been effective, particularly in youth populations, most notably the RugbySmart scheme in New Zealand $^{20}$ and BokSmart in South Africa. ${ }^{21} 22$

The primary reasons cited for wearing headgear related to the prevention of minor injuries $55 \%$ of the raw data responses), with only $10 \%$ of responses indicating concussion prevention as a motivating factor. Previous research found that $38 \%^{18}$ and $62 \%^{17}$ of players believed headgear could prevent concussions. These studies used small samples from the $\mathrm{USA}^{18}$ and Canada. ${ }^{17}$ This difference in player attitudes between the present findings and previous studies may relate to the country in which the research was conducted. In the USA and Canada, other contact sports such as american football and ice hockey are more popular than rugby and played from a young age. Since protective headgear is mandatory in these sports and has been found to reduce the incidence of concussion, ${ }^{11} 23$ players from these countries may also believe that headgear is effective at preventing concussion when worn in rugby union. In the present study, the large proportion of responses relating to the prevention of minor injuries suggests that in the UK population sampled, there was an increased awareness that protective headgear is designed only to prevent superficial head injuries, a fact supported by research. ${ }^{8-11}$ It is possible that the recent drive in the UK towards improved concussion awareness might explain why players appear better informed about the prevention of head injuries compared with other nations. The Rugby Football Union's's Headcase initiative ${ }^{24}$ was launched in 2013 with the aim of providing 
Table 2 Reasons for non-regular/no use of protective headgear

\section{Higher order themes (\% of responses) Example responses}

Discomfort (36\%) Feeling of being 'enclosed' and an irritant whilst playing due to chafing and sweating.

Haven't found a comfortable scrum cap.

I used to wear it but found that I got too hot when playing in it.

I have a big head so it is tight.

Don't require one (24\%) I am a full back and do not require that level of head protection.

I'm a scrum half and don't feel the need.

I don't think my position on the wing requires one and I'm not used to wearing one.

Never felt the need for it, as it is not compulsory.

$\begin{array}{ll}\text { Restricted senses }(23 \%) & \text { Disrupts hearing - feel like it impairs my cognitive functioning. } \\ \text { I think it hinders my vision and play more than it helps. } & \text { I am unable to hear the game, teammates and officials with headgear on. } \\ \text { I feel restricted when I wear it. I don't like the feel of it in open play as I feel like I } \\ \text { struggle to see wearing it. }\end{array}$

They aren't useful (11\%) I'm not convinced it offers that much protection.

I have never seen any study that shows Scrum Hats are an effective measure to protect from concussion.

Doesn't stop concussion. Only helps to stop cuts but l've been told hair does the same job.

Stigma $(4 \%)$

I don't think it looks good on me.

Perceived social perception of other players may see you as 'soft' for being a back and wearing headgear.

False sense of security (2\%)

Encourages reckless play with a feeling of invincibility.

I feel that the headgear doesn't actually give much protection but when you are wearing it you feel safer so could potentially be more inclined to put yourself at more danger than is necessary.

concussion education to all levels of the game, focusing on players and on coaches, match officials and parents. The guidance makes specific reference to the lack of concussion prevention offered by protective headgear and focuses on education of correct tackle technique. Such specific initiatives targeting all levels of the game may account for the increased awareness of the limitations of headgear in preventing concussions seen in the present study. In addition, increased media exposure might have increased awareness of the limitations of headgear use. For example, an article published in the UK media in 2014 suggested that headgear use could in fact increase the risk of concussions rather than reduce it, providing players with a false sense of security thereby increasing the risk of reckless play. ${ }^{25}$

Of those players who wore headgear, $13 \%$ of responses related to increased confidence as a motivation for its use. The association between headgear use and injury prevention seen in this group may support the notion that wearing headgear gives some players confidence not to worry about getting injured. It has been suggested that some players can become overly reckless when wearing protective equipment. ${ }^{26}$ For a proportion of players, wearing headgear may facilitate a 'false sense of security' and a 'lead with your head approach' that could result in an increased risk of injury. ${ }^{17}$ Previous studies found $67 \%$ of youth players felt more confident and able to tackle harder when wearing headgear, ${ }^{16}$ while senior players who believed headgear prevented concussions were four times more likely to play with an aggressive technique. ${ }^{18}$ Although confidence was identified as an important theme, it did not appear to be as important as previous studies had suggested ${ }^{16} 18$ and might further indicate an increased awareness of the limitations of headgear in UK players. Of those players who wore headgear, $12 \%$ of responses related to increased confidence following a previous injury as a reason for wearing headgear. This finding supports previous research that found that a third of players wore headgear after suffering previous concussions. ${ }^{18}$ This is concerning given that research does not support the use of headgear in preventing serious head injuries. ${ }^{8-11}$

Of those individuals who did not wear headgear regularly, discomfort (36\% of responses) and the restriction of senses $(23 \%)$ were identified as two of the main reasons. Findings support previous research that found comfort and thermoregulation to be the two most important reasons for players not wearing headgear. ${ }^{16}$ These factors should continue to be considered 
by manufacturers to ensure that future designs are both comfortable and well ventilated while still providing adequate protection from superficial head injuries. Interestingly, only $11 \%$ of non-headgear wearers cited 'they don't work' as the major reason for choosing not to wear them. This suggests that even in this group there is still a belief that they may offer some benefit in reducing the risk of head injuries, serious or otherwise. Of non-regular wearers, $37 \%$ said they would consider wearing headgear in the future. Therefore, if manufacturers can address players' concerns about comfort, thermoregulation and restricted senses, more players might opt to wear headgear in training and matches.

Of all players surveyed, only 13\% 'agreed' or 'strongly agreed' that headgear should be mandatory for all players, lower than the $24 \%$ rate previously reported for senior players. ${ }^{17}$ Youth and female players as well as those with less years of playing experience were more inclined to believe headgear should be mandatory compared with subelite and semiprofessional/professional groups. These findings further support the need for educational programmes about the limitations of protective headgear at all levels of the game.

\section{STRENGTHS AND LIMITATIONS}

This was the first study of its kind to explore attitudes towards protective headgear in UK rugby union players. A strength of the study was its mixed-methods approach to exploring player attitudes. Specifically, combining descriptive and inferential statistics with a content analysis has supplemented understanding in this area. Due to similar general dimensions emerging in all groups, we did not consider playing subgroups' attitudes towards headgear use separately. Therefore, although our quantitative analysis revealed important differences in the attitudes between playing groups, we did not explore the reasons for wearing or not wearing headgear isolated to group. For example, a number of youth players who regularly wore headgear cited parental influences as a key factor. While beyond the scope of this study, research into the attitudes of parents and coaches towards headgear use is important to fully understand usage within youth rugby. This was the first study to examine attitudes towards headgear in women's rugby. However, due to a relative shortage of responses from female players $(n=78)$, any respondents over the age of 18 years were grouped together regardless of playing level. Therefore, this group comprised players with limited playing experience along with elite level players. Due to this disparity in experience, it was difficult to detect meaningful trends in this group.

\section{CONCLUSIONS}

The present study found that those that wore headgear did so primarily for the prevention of superficial head injuries, a benefit supported by scientific evidence..$^{8-11}$ There appeared to be a greater awareness in UK players that protective headgear was not effective at preventing concussion compared with previous studies. Continued education at all levels of the game is vital to ensure players are fully aware of the limitations of protective headgear, and players who wear it do not engage in overly reckless behaviours as a result.

Contributors All authors conceived the study and developed the data collection and protocol. PO developed the online survey, and JLR performed the statistical analysis on the data. All authors wrote the first draft of the manuscript and critically reviewed the work before approving the final version of the manuscript. All authors will act as study guarantors for this paper.

Competing interests None declared.

Patient consent Obtained.

Ethics approval Sheffield Hallam University Ethics Board, Sheffield, UK.

Provenance and peer review Not commissioned; externally peer reviewed.

Open Access This is an Open Access article distributed in accordance with the Creative Commons Attribution Non Commercial (CC BY-NC 4.0) license, which permits others to distribute, remix, adapt, build upon this work noncommercially, and license their derivative works on different terms, provided the original work is properly cited and the use is non-commercial. See: http:// creativecommons.org/licenses/by-nc/4.0/

(c) Article author(s) (or their employer(s) unless otherwise stated in the text of the article) 2017. All rights reserved. No commercial use is permitted unless otherwise expressly granted.

\section{REFERENCES}

1. Freitag A, Kirkwood G, Pollock AM. Rugby injury surveillance and prevention programmes: are they effective? BMJ 2015;350:h1587.

2. Gardner AJ, Iverson GL, Williams WH, et al. A systematic review and meta-analysis of concussion in rugby union. Sports Med 2014;44:1717-31.

3. Grady MF. Concussion in the adolescent athlete. Curr Probl Pediatr Adolesc Health Care 2010;40:154-69.

4. Harmon KG, Drezner JA, Gammons M, et al. American medical society for sports medicine position statement: concussion in sport. Br J Sports Med 2013;47:15-26.

5. Pfister T, Pfister K, Hagel B, et al. The incidence of concussion in youth sports: a systematic review and meta-analysis. $\mathrm{Br} J$ Sports Med 2016;50:292-7.

6. Kirkwood MW, Yeates KO, Wilson PE. Pediatric sport-related concussion: a review of the clinical management of an oft-neglected population. Pediatrics 2006;117:1359-71.

7. Yard EE, Comstock RD. Injuries sustained by rugby players presenting to United States emergency departments, 1978 through 2004. J Athl Train 2006;41:325-31.

8. Mclntosh AS, McCrory P, Finch CF, et al. Does padded headgear prevent head injury in rugby union football? Med Sci Sports Exerc 2009;41:306-13.

9. Marshall SW, Loomis DP, Waller AE, et al. Evaluation of protective equipment for prevention of injuries in rugby union. Int $J$ Epidemiol 2005;34:113-8.

10. Jones SJ, Lyons RA, Evans R, et al. Effectiveness of rugby headgear in preventing soft tissue injuries to the head: a case-control and video cohort study. Br J Sports Med 2004;38:159-62.

11. Schneider DK, Grandhi RK, Bansal $P$, et al. Current state of concussion prevention strategies: a systematic review and metaanalysis of prospective, controlled studies. Br J Sports Med 2016:bjsports-2015-095645. [Epub ahead of print 1 Jun 2016].

12. Kahanov L, Dusa MJ, Wilkinson S, et al. Self-reported headgear use and concussions among collegiate men's rugby union players. Res Sports Med 2005;13:77-89.

13. Kemp SP, Hudson Z, Brooks JH, et al. The epidemiology of head injuries in English professional rugby union. Clin J Sport Med 2008;18:227-34.

14. Hollis SJ, Stevenson MR, McIntosh AS, et al. Incidence, risk, and protective factors of mild traumatic brain injury in a cohort of Australian nonprofessional male rugby players. Am J Sports Med 2009;37:2328-33.

15. Mclntosh AS, McCrory $P$. Headgear effectiveness in under 15 s rugby union. Br J Sports Med 2001;35:167-9. 
16. Finch CF, Mclntosh AS, McCrory P. What do under 15 year old schoolboy rugby union players think about protective headgear? $\mathrm{Br}$ J Sports Med 2001;35:89-94.

17. Pettersen JA. Does rugby headgear prevent concussion? Attitudes of Canadian players and coaches. $\mathrm{Br} J$ Sports Med 2002;36:19-22.

18. Menger R, Menger A, Nanda A. Rugby headgear and concussion prevention: misconceptions could increase aggressive play Neurosurg Focus 2016;40:1-7.

19. Miles MB, Huberman M, Saldana J, et al. Qualitative data analysis. 3rd edn. Londan: Sage, 2013.

20. Gianotti SM, Quarrie KL, Hume PA. Evaluation of RugbySmart: a rugby union community injury prevention programme. J Sci Med Sport 2009;12:371-5.

21. Viljoen W, Patricios J. BokSmart - implementing a National Rugby Safety Programme. Br J Sports Med 2012;46:692-3.
22. Brown JC, Verhagen E, Knol D, et al. The effectiveness of the nationwide boksmart rugby injury prevention program on catastrophic injury rates. Scand J Med Sci Sports 2016;26:221-5

23. Benson BW, Hamilton GM, Meeuwisse WH, et al. Is protective equipment useful in preventing concussion? A systematic review of the literature. Br J Sports Med 2009;43 Suppl 1:i56-i67.

24. Union RF. Concussion: Headcase [Web page on the internet]. http:// www.englandrugby.com/my-rugby/players/player-health/ concussion- headcase/ (Accessed 2 Feb 2017).

25. Briggs $S$. Headguards in rugby would add to the concussion problem, not solve it, says doctor. The Telegraph 2014 http://www. telegraph.co.uk/sport/rugbyunion/news/11150094/Headguards-inrugby-would-add-to-the-concussion-problem-not-solve-it-saysdoctor.html (Accessed 2 Feb 2017).

26. Hagel B, Meeuwisse W. Risk compensation: a "side effect" of sport injury prevention? Clin J Sport Med 2004;14:193-6. 